\title{
Congenital Myotonic Dystrophy
}

\section{Craig Campbell*}

Clinical Neurological Sciences, Department of Epidemiology and Community Medicine, Department of Pediatrics University of Western Ontario, London, Canada

\begin{abstract}
Congenital Myotonic Dystrophy (CDM) is an uncommon form of myotonic dystrophy, seen only in Myotonic Dystrophy type 1 (DM1), which results from genetic anticipation. The affected infant suffers respiratory and feeding problems in association with hypotonia and weakness. These issues and the other associated multisystem problems combine to make CDM a condition requiring a large investment of health care resources. Currently unanswered pertinent questions remain about CDM ranging from the responsible pathogenic mechanisms through to the impact of the disease on family quality of life. This review explores the general pathophysiology of DM1 and the relevance of these mechanisms to CDM, followed by a review of the epidemiologic and clinical aspects of CDM. In addition monitoring and therapeutic interventions to facilitate the care of those patients with CDM and their families are provided.
\end{abstract}

Keywords: Myotonic Dystrophy; Congenital; DMPK; Trinucleotide repeat disorder

\section{Introduction}

Myotonic dystrophy (DM) is an autosomal dominant, multisystem disorder characterized by muscle weakness and myotonia commonly beginning in early adulthood, however, the most dramatic presentations of myotonic dystrophy is that occurring in the neonatal period, or Congenital Myotonic Dystrophy (CDM, OMIM 160900).

Two loci for the dystrophic myotonias are known and described as DM1 and DM2. At both loci inheritance is autosomal dominant, with DM1 associated with a CTG trinucleotide expansion on chromosome $19 \mathrm{q} 13.3$ and DM2 with a CCTG tetranucleotide expansion at 3q21. DM2 is not associated with a CDM phenotype, (although neonatal club foot has been once reported [1]) and so it will not be discussed further, however much of the discussion on pathogenesis related to DM1 is applicable to DM2, as will become evident below.

DM1 is the most commonly encountered hereditary muscle disease in adults with an incidence of $1 / 8000$ [2]. Most adults will present with mild distal limb and facial weakness that is slowly progressive. Grip myotonia, or an inability of muscle relaxation following contraction, is another commonly recognized early symptom. Other associated symptoms include: cataract formation, premature balding, insulin resistance, male infertility, cardiac arrhythmias, dysphagia and hypersomnolence. The clinical presentation is variable both in its severity and age of onset and many adults at presentation are not fully aware of the degree of their motor impairment. Due to the variable symptoms and severity, many affected families may only recognize the disease when confronted with a child with CDM.

This review will cover the genetic and pathophysiologic aspects of myotonic dystrophy in addition to the epidemiologic and clinical aspects of the congenital form of DM. For the section specifically on CDM a systematic search of articles using the terms "congenital myotonic dystrophy" and "congenital DM1" in MEDLINE-Ovid, EMBASE, Pubmed, Cochrane Library and PsychINFO was performed and reference lists searched.

\section{Genetics and Pathophysiology}

The gene associated with DM1 is the Myotonic Dystrophy Protein Kinase (DMPK) gene and codes for a $75-80 \mathrm{kDa}$ protein kinase that is located principally in heart and skeletal muscle, with much smaller amounts expressed in smooth muscle and non-muscle tissues [3]. The normal protein localizes to neuromuscular junctions [4], sarcoplasmic reticulum [5] and intercalated discs in the heart myocyte [6]. The functions of DMPK are manifold including: cell shape determination $[4,7]$ and effects on excitation coupling through calcium homeostasis [8].

Myotonic dystrophy is considered a disease of unstable nucleotide repeat expansion and the specific pathophysiology of DM1 will be described, however the interested reader is directed toward published general reviews on nucleotide repeat disorders $[9,10]$. The genetic defect in DM1 is unique in that the area of abnormally expanded CTG nucleotides is located in a 3' intron, or an untranslated region of the gene. This repeated region of CTG nucleotides exists in most people with a normal range of 3-35 repeats. The premutation state is considered at a range of 36-50 repeats. The disease DM1 is seen with repeat numbers greater than 50 , with increased severity (potentiation) and earlier age of onset (anticipation) associated with larger repeats. This relationship is true within a kindred, although the correlation is less than perfect when individuals with similar repeat size from different kindred's are examined. Classic adult onset disease is typically associated with a repeat size of 100-1000, whereas those with childhood or congenital onset usually have over 1000 repeats. Ascertainment of CTG repeat lengths is based principally on serum testing and one should be aware that different tissue types may display somatic mosaicism with varied degrees of CTG expansion [11]. A reference showing different classification systems used to group repeat expansion sizes is provided in Table 1.

The principal pathogenesis is related to the effects of large

*Corresponding author: Craig Campbell, Section of Pediatric Neurology, Children's Hospital of Western Ontario, 800 Commissioners Rd. E, London, Tel: 519-685-8332; Fax: 519-685-8350; E-mail: craig.campbell@Ihsc.on.ca

Received December 26, 2011; Accepted January 16, 2012; Published January 23, 2012

Citation: Campbell C (2012) Congenital Myotonic Dystrophy. J Neurol Neurophysiol S7. doi:10.4172/2155-9562.S7-001

Copyright: (c) 2012 Campbell C. This is an open-access article distributed under the terms of the Creative Commons Attribution License, which permits unrestricted use, distribution, and reproduction in any medium, provided the original author and source are credited. 
accumulations of mutant mRNA in the nucleus of cells. Discovery of the responsible gene for DM2 in a completely different area of the genome with a similar type of repeat expansion, a tetranucleotide, CCTG, with nuclear similar inclusions supports this theory. In accordance with this theory when large CTG trinucleotide expansions were added to the genome of mice (HSA-LR mouse model) they produced symptoms of myotonia and muscle degeneration [12]. Further to these observations it has been shown that large mRNA (messenger RNA) sequences form hairpin configurations that cannot pass normally into the cytoplasm for translation, with accumulation of abnormal mRNA inclusions [13].

This mutant mRNA has an impact on a class of nuclear proteins called mRNA binding proteins. Messenger-RNA binding proteins have a number of important cellular functions, but the splicing of mRNA into different isoforms is particularly relevant to DM1. Coding RNA can be destined for several different forms of end product protein depending on tissue type and developmental stage as well as other environmental factors and the mRNA binding protein is vital in regulating the expression of the appropriate final protein based on splicing patterns [14]. The Muscleblind (MBNL) family and CUGbinding protein 1 (CUG-BP1), are two such proteins implicated in the pathophysiology of DM1. The mutant mRNA binds specifically to MBNL1 protein, and sequesters this protein in the large nuclear mRNA inclusions. The consequences of reduced MBNL1 protein has been examined in both a MBNL1 knockout and HSA-LR mouse models which demonstrated phenotypic and mRNA splicing differences seen in DM1 and other mouse models of DM1 $[15,16]$. The splicing differences induced by a reduction in MNBL are directed toward an arrest of the normal transition to adult isoforms of a set of MNBL sensitive proteins [15]. More recently in the HSA-LR model it has been demonstrated that when MNBL is over-expressed, by transduction with an adenoviral vector injected into the tibialis anterior muscle, in an effort to supersaturate the mutant mRNA nuclear inclusions, the cellular consequences of mutant mRNA can be reversed [17]. In this study not only were protein splicing patterns reversed, but myotonic discharges on EMG improved as well, for a period of 43 weeks.

In contrast toxic mRNA acts to increase activity of CUG-BP1. Enhanced activity levels of CUG-BP1 causes RNA splicing changes that appear to be equally responsible for the DM1 phenotype [14]. Recently Ho [18] has shown that proteins normally altered by CUG-BP1 may be subject to splicing patterns that are directed toward the fetal isoforms of the protein, which could help to explain the immature muscle pattern is seen in those with congenital DM. Interestingly, only in DM1 are CUG-BP1 binding protein concentrations elevated and thus may explain the differences seen between DM1 and DM2, including the presence of a pediatric and congenital form of the disease. In support of increased CUG-BP1 being a primary determinant of DM1, Mahadevan [19] induced DM1-like phenotypes and splicing patterns in a mouse model with over expression of CUG-BP1. This unique model created the high cellular concentrations of CUG-BP1 via inducible over

\begin{tabular}{|l|l|l|l|}
\hline $\begin{array}{l}\text { Scale } \\
\text { Classification }\end{array}$ & $\begin{array}{l}\text { Approximate } \\
\text { number of repeats }\end{array}$ & $\begin{array}{l}\text { Approximate size } \\
\text { of expansion } \\
\text { (Kilobase) }\end{array}$ & $\begin{array}{l}\text { Usual Clinical } \\
\text { phenotype }\end{array}$ \\
\hline $\mathrm{E}_{0}$ & 35 to $<50$ & No obvious expansion & Pre-mutation \\
\hline $\mathrm{E}_{1}$ & 50 to $<500$ & $0<1.5$ kilobase & Classic adult onset \\
\hline $\mathrm{E}_{2}$ & 500 to $<1000$ & $1.5<3.0 \mathrm{~kb}$ & Adolescent onset \\
\hline $\mathrm{E}_{3}$ & 1000 to $<1500$ & $3.0<4.5 \mathrm{~kb}$ & $\begin{array}{l}\text { Childhood and } \\
\text { congenital onset }\end{array}$ \\
\hline $\mathrm{E}_{4}$ & $\begin{array}{l}\text { Equal or }>1500 \\
\text { repeats }\end{array}$ & $>4.5 \mathrm{~kb}$ & Congenital onset \\
\hline
\end{tabular}

Table 1: Comparison of classification systems for myotonic dystrophy. expression of short segment CUG repeat mRNA (short segments were slightly expanded mRNA but were not long enough to form nuclear inclusions or sequester MNBL). The altered splicing, muscle histology and cardiac conduction defects induced by high CUG-BP1 in this model were also reversible once expression was turned off.

A balance between the roles of MNBL and CUG-BP1 appears to exist. Under expression of MNBL or over expression of CUG-BP1 in mouse models, or a combination of both situations as exists in human DM1, manifests in a multisystem illness due to modifications of RNA splicing. In DM1, one function that is disrupted is the transport of chloride channels to the myofiber membrane with resultant impaired chloride conductance, which leads to myotonia in DM1. Many other proteins are altered in both DM1 and animal models including insulin receptors [20], calcium channels on the sarcoplasmic reticulum [15], BIN1 [21] and cardiac troponin transcripts [18]. Even MNBL1 splicing itself seems to be influenced by MNBL1 [15]. Splicing abnormalities in the glutamate NMDA receptor in the CNS, tau protein $[22,23]$ and SLITRK [24] may be the reason for cognitive impairment and other brain abnormalities.

At this time there are no clinically available curative or disease modifying therapies for DM, however, understanding the molecular pathogenesis will generate rationale therapeutic targets that are described in a recent comprehensive review article [25].

\section{Congenital Myotonic Dystrophy}

In DM1, increasing severity and earlier age of onset can occur over subsequent generations as the unstable trinucleotide repeat carried by the parent, almost always the mother, expands with gametogenesis. This phenomenon is known as genetic anticipation and leads eventually to an infant with congenital myotonic dystrophy (CDM). First described in 1960 [26], a wide clinical spectrum is recognized but the classic symptoms are hypotonia, weakness, feeding difficulties and mechanical respiratory failure requiring intubation and ventilation immediately after birth.

Currently, it is not clear if the pathogenesis of CDM is similar to adult DM. The clinical features are different, with hypotonia and weakness involving proximal and distal muscles and no myotonia initially in CDM. Also other system involvement is much less common with the exception of cardiac conduction defects and cognitive impairment. Furthermore, clinical investigations have shown a pattern of muscle strength improvement in the first years of life prior to gradual progressive wasting and weakness similar to that seen in adults.

The muscle histology also differs with no evidence of dystrophic changes, but rather features of a more immature muscle pattern with central nuclei and peripheral sarcoplasmic halos in small round fibres resembling normal myotubes [11,27]. Ultrastructurally, there is a reduction seen in the contractile elements in both skeletal and cardiac muscle [11]. This muscle immaturity appears to improve which has been demonstrated in patients undergoing successive muscle biopsy [28]. Other tissue types may also show unexpected degrees of histologic immaturity as well such as lungs [11]. Research has suggested that CDM satellite cells give rise to myoblasts that have poor differentiation, impaired cell fusion and reduced regenerative capacity [29], and to date emerging evidence suggests a role of DMPK in myotube formation and changes in amount and localization during muscle cell differentiation [4]. In those with CDM in the first months of life DMPK staining appears weak, whereas by 2 to 9 years of age there is a more normal staining pattern of DMPK in the muscle sarcolemma [30]. Whereas in 
adult DM1 there is typically an under-expression of DMPK transcript, both over and under-expression has been demonstrated in those with CDM [31,32]. In myoblast cell lines an over-expression of full length DMPK cDNA caused poor myoblast fusion potential [33], which the authors suggest may be a factor in CDM patients.

In keeping with the adult form of DM1, expanded mutant mRNA appears to accumulate in the nucleus [29], and insulin receptor isoforms are different in CDM muscle than controls [31]. Little is known about other mRNA splicing patterns or outcomes on cellular proteins and channels in CDM muscle. However, one study examining mRNA splicing differences in Myotubularin Related Protein 1 (MTMR1), from four CDM subjects all had splicing abnormalities not seen in controls or in those with congenital myotubular myopathy [34]. If MTMR1 is important in myocyte maturation, as suggested, then splicing defects appear to be a precipitant for muscle immaturity. Sodium channel density is reduced and faster recovery rate compared to controls have been shown in CDM muscle culture, which may be due to splicing differences or abnormal regulation by DMPK [35].

In the past there was a question of a potential maternal factor that accounted for the maternal transmission in CDM and it appeared that serum from mothers of those with CDM could induce maturational muscle arrest in mice [28]. Other genetic mechanisms that may account for maternal inheritance such as genomic imprinting [36] and mitochondrial DNA abnormalities [37] have not shown any differences from controls. The imbalance between MNBL and CUGBP1 mRNA binding proteins potentially shifting protein isoforms toward a more persistent fetal pattern is attractive as a theory for the muscle immaturity seen in CDM. Supporting this, a mouse model of CUG-BP1 over-expression showed high newborn mortality [38]. In the affected survivors no apparent improvement of muscle strength was seen, unlike children with CDM. Most likely combinations of DMPK alterations, mRNA binding protein changes and as yet unknown factors account for the unique features of CDM, as of yet there is no animal model of DM1 produces a typical 'congenital' DM phenotype.

\section{Epidemiology}

Amongst series of hypotonic infants the rate of those with CDM ranges from $12-16 \%[39,40]$. Although the incidence of CDM has been estimated at one in every 3500 to 16000 births [Wesstrom ref 41, ref $42,43]$, however these have not used population based methods. The author has recently completed a 5 year prospective active surveillance study in Canada, using the Canadian Pediatric Surveillance Program, a platform for rare disease surveillance. Using this methodology, with a clear definition of CDM that included the need for medical intervention in the neonatal period, 38 children were identified with CDM over the time period March 2005-Feb 2010. Using live birth data for the same time period an incidence of 2.1/100,000 (or 1/47,619) live births [Campbell personal communication].

Often it is not clear in studies the definition of CDM and so there remains uncertainty, without patient descriptions, if labels of CDM are being applied based on molecular testing, need for neonatal ventilation, feeding support, hypotonia or even maternal history alone. To ensure a uniform case definition for CDM, we propose that, an affected child may only be considered as having the congenital form of the disease if they (or their mother) have a genetically confirmed DM1 diagnosis and the child dies or requires hospitalization or medical intervention in the newborn period (first month of life) due to myotonic dystrophy symptoms. This provides a clear pragmatic definition of CDM and avoids having mildly affected children with a positive family history being classified with CDM where the family history precipitates genetic testing. All other children with DM1 should be labelled as childhood or pediatric DM1.

\section{Clinical Genetics}

The child with CDM is often the index case that then provokes the diagnosis of DM1 in the mother and serves as a focal point for genetic testing and diagnosis for entire families. The author has previously reported between $48-58 \%$ of the CDM children were the index case for their family [41] [Campbell personal communication- this is the CPSP study]. This seems a high number given that most mothers of children will themselves have expansions between 500-1500 repeats which is usually associated with a moderate clinical phenotype [42]. Rare cases of paternal transmission causing CDM have been reported $[43,44]$.

Larger expansion sizes within a family are linked to earlier onset of disease. A study of 109 individuals from 17 families revealed that $56 \%$ of affected individuals with an expansion size of greater than 4.5 $\mathrm{kb}$ (> 1500 CTG repeats) by southern blot had congenital onset (and all subjects in this group had onset prior to 25 years of age) contrasted with the group of individuals with a less than $1.5 \mathrm{~kb}$ expansion which had no cases of congenital onset and only one case childhood onset [45]. Within parent-child pairs in this study, children had a greater than two category increase in expansion size in 33 of 37 pairs and in all these cases the child had an earlier onset of disease. Interestingly, children with a similar expansion size as their parent also displayed an earlier age of onset of symptoms in 15 of 17 cases. It has been suggested that if a mother has one child with CDM then subsequent children with DM1 will also have CDM [46]. In another study of 124 maternal-child pairs a maternal expansion size of greater than 300 was associated with a $59 \%$ risk of CDM, versus only a $10 \%$ if the expansion was below this value [47]. However there is considerable variability as mothers with very small expansion sizes can have children with CDM [48] and case series of CDM children have demonstrated that between $10-18 \%$ of children can have relatively small expansion sizes $(<1000$ repeats) not normally considered a risk for congenital onset $[41,42,48]$. The lowest expansion size associated with CDM phenotype requiring ventilation support is 400 repeats [49]. Similarly, even at large expansion sizes the disease may not be severe, as those with $>1500$ repeats may have had no need for medical intervention early in life [41]. Rarely, the trinucleotide expansion can decrease in size across a kinship [48].

Prenatal testing is possible with chorionic villus sampling or amniocentesis. Paternal inheritance resulting in CDM is very unlikely, and in these cases the mean expansion in the trinucleotide number is relatively low at 56 repeats, with cases of contractions in CTG repeat size on record [50]. Conversely, with maternal transmission the mean CTG repeat increase is 948 [51]. Genetic counselling to help affected mothers understand the risks of disease transmission has been limited due to the variable correlation between the trinucleotide repeat length and clinical symptoms. In fact, it is clear that women are not interested in pre-natal testing exactly for this reason [52], and consensus statements have suggested caution in using genetic information as the sole indicator of risk of CDM [53].

Referral for genetic counselling services should be made for every family regardless of future child bearing plans as many women do not understand the risks of transmission [52]. Approximately half of the mothers in one series felt that being affected by DM1 did not have an influence on their child bearing decisions and all were knowledgeable about DM1 symptoms [52]. Other issues which may be related to pre-natal decision making include religious/culture values, 
cognitive status of mothers, and inadequate understanding or lack of information. Asymptomatic minors of parents with DM1 are generally not tested due to inability to ensure fully informed decision making at a young age [53]. It is now clear that some otherwise asymptomatic children with DM1 can have cardiac arrhythmias causing death and so all unconfirmed asymptomatic siblings could be offered yearly electrocardiogram.

\section{Clinical Characteristics}

CDM may first manifest in utero as miscarriage, polyhydramnios, reduced fetal movement, premature delivery and still birth [54-58]. Neonates may need substantial resuscitative effort in the immediate postnatal period due to poor respiratory effort. Low Apgar scores may be a reflection of facial weakness, reduced tone and poor respiratory effort and not necessarily reflect a hypoxic-ischemic situation. Cord blood $\mathrm{pH}$ and initial blood gas should be used as a more reliable marker of physiologic compromise. Additionally, evidence of multisystem organ dysfunction and the presence of persistent pulmonary hypertension, which has been described in infants with CDM [59], should be indicators of actual hypoxic-ischemic encephalopathy. Neuroimaging must be interpreted in light of the supporting clinical findings before attributing changes to HIE.

On examination, the newborn often demonstrates a characteristic facial weakness with a tented upper lip, mild ptosis and wasting of temporalis muscles giving the face a long thin appearance (Figure 1). Diffuse hypotonia and hyporeflexia, at times associated with arthrogryposis, is evident on motor exam. Although not easily distinguished from hypotonia, weakness is also evident by a lack of spontaneous anti-gravity movement. The feet are often in a fixed or mobile club foot. Sensory system examination should be normal; however withdrawal responses and facial reaction to noxious stimuli will be difficult to judge due to motor impairment. Changes in heart rate or respiratory signs may be the only indicator of discomfort to noxious stimuli. Undescended testes are common in CDM, as in most congenital myopathic conditions [54]. Head size should be measured and followed due to a common occurrence of ventriculomegaly and even non-communicating hydrocephalus [60,61]. Although rarely done, due to the ease and specificity of genetic testing, the EMG performed in the newborn period is usually unremarkable. Rarely the EMG may demonstrate myotonic discharges [62] despite no evidence of clinical myotonia. One may also find myotonic discharges beyond the neonatal period before clinical myotonia is evident [62].

In the initial hospital period the greatest problems result from respiratory and feeding issues, but a list of all medical complications can be found in Table 2. Essentially all children will have substantial feeding and/or breathing difficulties requiring a period of assisted feeding and/or assisted ventilation requiring hospital admission for longer than that expected for their gestational age. Feeding may be started with nasogastric tube initially but slow GI motility, reflux or constipation may dictate the use of total parenteral nutrition. Motility agents such as metoclopromide can be helpful in improving gastric motility [63] with antacids improving reflux induced pain. Establishing oral feeding is challenging in those with substantial facial and oropharyngeal weakness or in those requiring prolonged ventilation. Long term nasogastric feeding or gastric-tube insertion is appropriate until facial strength improves.

Mechanical respiratory failure due to muscle weakness and/ or pulmonary hypoplasia is the main respiratory problem. Other respiratory factors include thin ribs and raised right hemi-diaphragm.
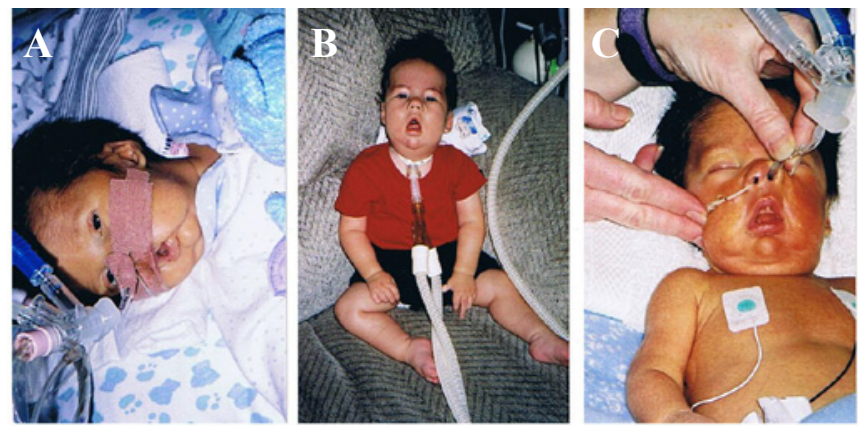

Figure 1: Characteristic facial weakness with a tented upper lip, mild ptosis and wasting of temporalis muscles giving the face a long thin appearance.

\begin{tabular}{|l|c|}
\hline Medical Problem & Reference \\
\hline ASD and PDA & {$[97]$} \\
\hline Cholelithiasis/cholestasis & {$[99]$} \\
\hline Chromosomal inversions & {$[101]$} \\
\hline Cystinuria & {$[96]$} \\
\hline Double outlet right ventricle & {$[102]$} \\
\hline Hernia & {$[62]$} \\
\hline Hydrops fetalis & {$[93],[94]$} \\
\hline Hyperinsulinism & {$[100]$} \\
\hline Mobieus syndrome (unilateral facial weakness and abducens & {$[102]$} \\
\hline palsy) & {$[95],[59]$} \\
\hline Persistent Pulmonary Hypertension & {$[98]$} \\
\hline Persistent tunica vasculosa lentis & {$[89]$} \\
\hline Progressive hypertrophic cardiomyopathy & {$[66]$} \\
\hline Seizures & {$[41]$} \\
\hline Strabismus & {$[61]$} \\
\hline Ventriculomegaly and hydrocephalus & {$[64]$} \\
\hline Vesico-urethral reflux & {[} \\
\hline
\end{tabular}

Table 2: Uncommon Medical Problems in the Neonatal Period.

Empirical management of respiratory function includes mechanical ventilation as well as medical therapies to stimulate respiratory function such as theophylline [64], caffeine [65] and aminophylline $[61,65]$. Surgical procedures such as plication of the diaphragm may help improve lung volumes. A gradual progression from full ventilatory support to nasal continuous positive airway pressure will facilitate independent ventilation.

Several published pediatric case series list CDM mortality rates in the range of 16 to $41 \%$ [41,55-57,61,66] although some of these studies include withdrawal of supportive care. The cause of death is generally respiratory insufficiency. By constructing a life table using 115 patients with a diagnosis of CDM, Reardon et al. [55] were able to show a $50 \%$ mortality by the mid-thirties. The most common causes of death were related to respiratory illness and cardiac arrhythmias.

Until recently, it was not an uncommon belief that children with CDM ventilated for longer than thirty days all died and that prolonged treatment was futile [61,67]. In a retrospective review of 23 children, Campbell et al. [41] have demonstrated that this is not the case. In this report, all children $(n=8)$ requiring ventilation over 30 days became independent of the ventilator. Three deaths did occur in this group at 8 months, 10 months and 11 years. The overall mortality rate was $20 \%$ $(4 / 20)$, regardless of ventilation status and excluding those who had life support withdrawn $(\mathrm{n}=3)$, with follow-up durations between 2 and 16 years. The belief that all children ventilated greater than 30 days did 
not survive complicates efforts to understand the natural history of $\mathrm{CDM}$, as many children in the past could have had withdrawal of care at this 30 day time point. With recent reports of ventilator-free survival after prolonged ventilation $[41,64,65,68]$ more families may opt for this approach. Currently long term ventilation has been described in a child with $>2500$ repeats, who at age nine years still requires overnight ventilation. He remains severely impaired from a motor perspective but cognitively is only mildly delayed [69]. These data contradict the position statement, of the $117^{\text {th }}$ European Neuromuscular Conference Workshop Report [70], that the prognosis for weaning ventilation in CDM patients after four weeks of ventilation is poor. Appropriate counselling for parents about withdrawal of life support should include accurate information about the long term improvement in respiratory function and the option of long term ventilation.

Respiratory infections and GI dysmotility or pseudo-obstruction are the principle long term complications in children with CDM, requiring an average of approximately one admission to hospital per year [41]. Orthopedic complications such as joint contracture, scoliosis [71] and fragility fracture should be monitored but little data is available on their prevalence in CDM. Cardiac conduction defects and arrhythmias need to be assessed through yearly ECG and/ or holter monitoring. Approximately $80 \%$ of children with $\mathrm{CDM}$ will have some ECG abnormality including abnormal Q-waves, ventricular hypertrophy, tachycardia, prolonged PR or QRS duration, and infranodal conduction defects [71]. Strabismus occurs in approximately one quarter of children and cataracts are typically a late and uncommon finding within the pediatric age range [56].

Although motor skills do improve over time, developmental motor and cognitive delay can be expected. Case series data show that children often will not walk before 18 months, but essentially all become independently mobile between age two and five years [56]. The rare child remains wheelchair dependant. Recently, CTG repeat size has been shown to correlate to motor function in a group of severe CDM patients [72]. Neck flexors and trunk flexors are usually the weakest muscles on bedside testing [71]. Functionally, jumping and heel walking are more difficult than stairs and running [72]. Oro-facial motor function is also impaired due to lip, tongue and facial weakness resulting in drooling, dysarthia and chewing/swallowing difficulties [73].

\section{Mental Status}

Some degree of cognitive impairment is found in CDM children, which appears to be due to a static encephalopathy. In six children with CDM tested with the Griffiths Mental Development Scales between 17 and 48 months of age, the developmental quotients ranged from 33 to 79 [74], and the deficits, were not accounted for even when excluding the locomotor subscale. Scores on intelligence testing is typically subnormal. One study of 18 children had percentile IQ scores ranging between 43 and 74 [56], a finding supported by other studies [54,71,75,76]. Not surprisingly, special educational supports will be needed by almost all children [77]. Of note, the severity of brain abnormality on imaging does not appear to correlate strongly with the level of intelligence [75,78]. Additionally, the length of the CTG expansion does not necessarily translate into the most severe cognitive changes [75].

Attention deficit-hyperactivity disorder and anxiety disorders have been noted more commonly in children with CDM [76], a finding also seen in those with childhood onset DM1 [79]. A case-control study of 8 children with CDM and age, gender and school matched controls found that those with CDM demonstrated greater problems with motivation, insecurity, disobedience and were more withdrawn. They also caused more classroom disturbance and were twice as likely to have high emotional psychiatric scores than controls [80]. This study suggested that multifactorial issues, other than the direct biological impact of $\mathrm{CDM}$, such as parental and sibling illness and poor recognition of facial emotions by teachers may be important to behavioral differences.

Autistic spectrum disorders have been noted in over $50 \%$ of children with CDM and the longer the repeat size seem to correlate with Autistic features [ekstrom 2008]. This was based on interviews by a psychologist using a standardized instrument for Autism testing. Autistic spectrum disorders have not been noted to be so high in other series [49] and given the mental retardation, delayed language development, and myopathic facial expression one can envision that assessing for autistic features may be challenging.

\section{Neuroimaging and Central Nervous System Pathology}

Head US and CT scanning can reveal ventriculomegaly, which is most commonly non-progressive $[78,81,82]$. MRI has been valuable in identifying white matter changes, which are common in CDM. In one series of seven patients, white matter hyperintensities were noted in all children on T2 weighted MRI and ranged from single, isolated lesions to diffuse, confluent high signal [78]. Diffusion tensor imaging appears to confirm this finding of diffuse abnormalities in white matter microstructure [83]. Most changes were periventricular area and the white matter signal change was associated with mild or moderate loss of white matter and corresponding ventriculomegaly. Hashimoto et al. [84] also showed ventriculomegaly and/or periventricular white matter changes in all seven of their patients, but also observed brainstem atrophy, thin corpus callosum and cerebellar white matter high signal change in some children. Similar findings are reported in adults with less frequency [84]. MR spectroscopy shows lower N-acetyl aspartate/ choline and creatine ratios compared to normal controls [85].

Few pathologic samples have been reported in any detail. Periventricular leukomalacia and hydrocephalus were noted in a set of five patients [57]. Another series showed mature neurons abnormally placed in white matter and cortical heterotopia in the cerebellar vermis [82]. Leptomeningial glioneuronal heterotopias have been reported in two children [86].

\section{Long Term Outcome}

Later in childhood myotonia and slowly progressive distal muscle weakness become clinically evident as the disorder begins to take on the more characteristic adult form [54]. Although uncommon complications in the pediatric age group, yearly assessment for cataract formation and hyperglycemia is part of routine care.

Although gastrointestinal and orthopedic complications are clinically relevant problems later in life there is few such focused literature in CDM patients. In a single site, long term follow-up of those with $\mathrm{CDM}$ the constipation rate was $34 \%$ and the scoliosis rate was $10 \%(n=71)$, but no clear definition of CDM is given and the severity of these problems is not detailed [55]. An examination of the orthopedic issues in 30 children with CDM shows that scoliosis (or kyphoscoliosis) is problematic in $30 \%$ with $10 \%$ requiring surgical correction [87]. Other less common problems included acquired heel cord contracture (23\%), hip abductor contracture (7\%), and lower extremity torsional malalignment signs (17\%). 


\begin{tabular}{|c|c|c|}
\hline & Baseline & Annually \\
\hline $\begin{array}{l}\text { Respiratory } \\
\text { [70] }\end{array}$ & $\begin{array}{l}\text { 1. Chest x-ray } \\
\text { 2. Respirology consultation } \\
\text { 3. FVC in the sitting position (if } \\
\text { FVC }<80 \% \text { then a supine FVC } \\
\text { should be performed) } \\
\text { 4. Overnight pulse oximetry (if FVC } \\
<60 \% \text { or child unable to perform } \\
\text { FVC eg. Under } 5 \text { years old) }\end{array}$ & $\begin{array}{l}\text { 1. FVC (see baseline) } \\
\text { 2. Overnight pulse } \\
\text { oximetry }\end{array}$ \\
\hline Cardiac & $\begin{array}{l}\text { 1. Echocardiography } \\
\text { 2. Electrocardiogram (ECG) }\end{array}$ & $\begin{array}{l}\text { 1. ECG } \\
\text { 2. If ECG abnormal a 24- } \\
\text { hour holter monitor }\end{array}$ \\
\hline Laboratory & $\begin{array}{l}\text { 1. Fasting glucose } \\
\text { 2. Thyroid stimulating hormone } \\
\text { (TSH) }\end{array}$ & $\begin{array}{l}\text { 1. Fasting glucose } \\
\text { 2. Thyroid stimulating } \\
\text { hormone }(\mathrm{TSH})\end{array}$ \\
\hline Ophthalmology & 1. Eye examination & 1. Eye examination \\
\hline Orthopedic & 1. Spine $x$-rays & \\
\hline Developmental & $\begin{array}{l}\text { Intelligence Quotient at age 5-7 } \\
\text { years }\end{array}$ & \\
\hline
\end{tabular}

Table 3: Recommended Schedule for Health Monitoring.

Cardiac arrhythmia and hypertrophic cardiomyopathy have been described $[88,89]$. In a study of seven asymptomatic adolescences with CDM all had some ECG or echocardiographic abnormality with atrioventricular and intraventicular conduction defects in the majority [90]. Some echocardiography differences include mitral valve prolapse and fractional shortening reduction in later childhood [90,91]. In case series one can conclude that fatal arrhythmias are a common cause of mortality $[41,55]$. Fatigue and daytime somnolence are reported in combined series of CDM and childhood onset DM1with a frequency as high as $71 \%$ and $52 \%$ respectively [92]. Electroencephalograms are normal and epilepsy is rare [75].

Appropriately, more interest has been placed on family and child quality of life for the assessment of outcomes in all areas of medicine. In DM, multiple factors can compromise patient and family quality of life. The disease involves both cognitive and motor impairment, which requires highly demanding care and external resources in many cases. Affected mothers are often dealing with their own health care issues. A high incidence of family breakup was noted in our retrospective review [41] reinforcing the need to understand the impact of DM on the family. No quality of life studies or even simple descriptions of family functioning have been carried out in the CDM population.

\section{Monitoring and Management}

Yearly clinical evaluations should occur in a pediatric neuromuscular clinic to assure child health, maternal health and monitor non-affected children who could develop symptoms. Table 3 outlines published guidelines for ventilatory monitoring [70] as well as a suggested investigation schedule from our clinic. Supportive management is the only currently available treatment. Anticipatory developmental support and facilitating resource allocation to optimize the educational environment is important.

\section{Conclusion}

Congenital Myotonic Dystrophy, although uncommon, remains an important pediatric neuromuscular disease. There remain many unanswered molecular and clinical questions. Understanding the natural history is perhaps the most paramount currently, so that accurate information can be given to parents. As treatments become available and we need to have high quality natural history studies, clinical outcome measure evaluations and DM1 registries that include pediatric patients.

\section{Acknowledgement}

Thank you to Shannon Venance for comments on drafts of the manuscript.

\section{References}

1. Renard D, Rivier F, Dimeglio A, Labauge P (2010) Congenital talipes equinovarus associated with myotonic dystrophy type 2. Muscle Nerve 42: 457

2. Harper PS H (2001) Myotonic Dystrophy. (3rdedn), Saunders.

3. Lam LT, Pham YC, Nguyen TM, Morris GE (2000) Characterization of a monoclonal antibody panel shows that the myotonic dystrophy protein kinase, DMPK, is expressed almost exclusively in muscle and heart. Hum Mol Genet 9: 2167-2173.

4. Beffy P, Barsanti C, Del Carratore R, Simi S, Benedetti PA, et al. (2005) Expression and localization of myotonic dystrophy protein kinase in human skeletal muscle cells determined with a novel antibody: possible role of the protein in cytoskeleton rearrangements during differentiation. Cell Biol Int 29: 742-753.

5. Ueda H, Shimokawa M, Yamamoto M, Kameda N, Mizusawa H, et al. (1999) Decreased expression of myotonic dystrophy protein kinase and disorganization of sarcoplasmic reticulum in skeletal muscle of myotonic dystrophy. J Neurol Sci 162: 38-50.

6. Kaliman P, Catalucci D, Lam JT, Kondo R, Gutiérrez JC, et al. (2005) Myotonic dystrophy protein kinase phosphorylates phospholamban and regulates calcium uptake in cardiomyocyte sarcoplasmic reticulum. J Biol Chem 280 8016-8021.

7. Jin S, Shimizu M, Balasubramanyam A, Epstein HF (2000) Myotonic dystrophy protein kinase (DMPK) induces actin cytoskeletal reorganization and apoptoticlike blebbing in lens cells. Cell Motil Cytoskeleton 45: 133-148.

8. Benders AA, Groenen PJ, Oerlemans FT, Veerkamp JH, Wieringa B (1997) Myotonic dystrophy protein kinase is involved in the modulation of the Ca2+ homeostasis in skeletal muscle cells. J Clin Invest 100: 1440-1447.

9. Ranum LP, Cooper TA (2006) RNA-mediated neuromuscular disorders. Annu Rev Neurosci 29: 259-277.

10. Pearson CE, Nichol Edamura K, Cleary JD (2005) Repeat instability mechanisms of dynamic mutations. Nat Rev Genet 6: 729-742.

11. Joseph JT, Richards CS, Anthony DC, Upton M, Perez-Atayde AR, et al. (1997) Congenital myotonic dystrophy pathology and somatic mosaicism. Neurology 49: 1457-1460.

12. Mankodi A, Logigian E, Callahan L, McClain C, White R, et al. (2000) Myotonic dystrophy in transgenic mice expressing an expanded CUG repeat. Science 289: $1769-1773$

13. Davis BM, McCurrach ME, Taneja KL, Singer RH, Housman DE (1997) Expansion of a CUG trinucleotide repeat in the 3 ' untranslated region of myotonic dystrophy protein kinase transcripts results in nuclear retention of transcripts. Proc Natl Acad Sci U S A 94: 7388-7393.

14. Faustino NA, Cooper TA (2003) Pre-mRNA splicing and human disease. Genes Dev 17: 419-437.

15. Lin X, Miller JW, Mankodi A, Kanadia RN, Yuan Y, et al. (2006) Failure of MBNL1-dependent post-natal splicing transitions in myotonic dystrophy. Hum Mol Genet 15: 2087-2097.

16. Kanadia RN, Johnstone KA, Mankodi A, Lungu C, Thornton CA, et al. (2003) A muscleblind knockout model for myotonic dystrophy. Science 302: 1978-1980.

17. Kanadia RN, Shin J, Yuan Y, Beattie SG, Wheeler TM, et al. (2006) Reversa of RNA missplicing and myotonia after muscleblind overexpression in a mouse poly(CUG) model for myotonic dystrophy. Proc Natl Acad Sci U S A 103: 11748-11753.

18. Ho TH, Bundman D, Armstrong DL, Cooper TA (2005) Transgenic mice expressing CUG-BP1 reproduce splicing mis-regulation observed in myotonic dystrophy. Hum Mol Genet 14: 1539-1547.

19. Mahadevan MS, Yadava RS, Yu Q, Balijepalli S, Frenzel-McCardell CD, et al. (2006) Reversible model of RNA toxicity and cardiac conduction defects in myotonic dystrophy. Nat Genet 38: 1066-1070.

20. Paul S, Dansithong W, Kim D, Rossi J, Webster NJ, et al. (2006) Interaction of muscleblind, CUG-BP1 and hnRNP H proteins in DM1-associated aberrant IR splicing. EMBO J 25: 4271-4283. 
21. Fugier C, Klein AF, Hammer C, Vassilopoulos S, Ivarsson Y, et al. (2011) Misregulated alternative splicing of BIN1 is associated with T tubule alterations and muscle weakness in myotonic dystrophy. Nat Med 17: 720-725

22. Leroy O, Dhaenens CM, Schraen-Maschke S, Belarbi K, Delacourte A, et al. (2006) ETR-3 represses Tau exons $2 / 3$ inclusion, a splicing event abnormally enhanced in myotonic dystrophy type I. J Neurosci Res 84: 852-859.

23. Hernández-Hernández $O$, Bermúdez-de-León $M$, Gómez $P$, VelázquezBernardino P, García-Sierra F, et al. (2006) Myotonic dystrophy expanded CUG repeats disturb the expression and phosphorylation of tau in PC12 cells. J Neurosci Res 84: 841-851.

24. Marteyn A, Maury Y, Gauthier MM, Lecuyer C, Vernet R, et al. (2011) Mutant human embryonic stem cells reveal neurite and synapse formation defects in type 1 myotonic dystrophy. Cell Stem Cell 8: 434-444.

25. Mulders SA, van Engelen BG, Wieringa B, Wansink DG (2010) Molecular therapy in myotonic dystrophy: focus on RNA gain-of-function. Hum Mol Genet 19: R90-97.

26. Vanier TM (1960) Dystrophia myotonica in childhood. Br Med J 2: 1284-1288.

27. Tachi N, Kozuka N, Ohya K, Chiba S, Kikuchi K (1996) CTG repeat size and histologic findings of skeletal muscle from patients with congenital myotonic dystrophy. J Child Neurol 11: 430-432.

28. Farkas-Bargeton E, Barbet JP, Dancea S, Wehrle R, Checouri A, et al. (1988) Immaturity of muscle fibers in the congenital form of myotonic dystrophy: its consequences and its origin. J Neurol Sci 83: 145-159.

29. Furling D, Coiffier L, Mouly V, Barbet JP, St Guily JL, et al. (2001) Defective satellite cells in congenital myotonic dystrophy. Hum Mol Genet 10: 2079-2087.

30. Tachi N, Kozuka N, Ohya K, Chiba S, Kikuchi K (1996) Immunocytochemica localization of myotonin protein kinase on muscle from patients with congenital myotonic dystrophy. Histol Histopathol 11: 869-871.

31. Furling D, Lam le T, Agbulut O, Butler-Browne GS, Morris GE (2003) Changes in myotonic dystrophy protein kinase levels and muscle development in congenital myotonic dystrophy. Am J Pathol 162: 1001-1009.

32. Laurent A, Costa JM, Assouline B, Voyer M, Vidaud M (1997) Myotonic dystrophy protein kinase gene expression in skeletal muscle from congenitally affected infants. Ann Genet 40: 169-174.

33. Sabourin LA, Tamai K, Narang MA, Korneluk RG (1997) Overexpression of 3'-untranslated region of the myotonic dystrophy kinase cDNA inhibits myoblast differentiation in vitro. J Biol Chem 272: 29626-29635.

34. Buj-Bello A, Furling D, Tronchère H, Laporte J, Lerouge T, et al. (2002) Musclespecific alternative splicing of myotubularin-related 1 gene is impaired in DM1 muscle cells. Hum Mol Genet 11: 2297-2307.

35. Bernareggi A, Furling D, Mouly V, Ruzzier F, Sciancalepore M (2005) Myocytes from congenital myotonic dystrophy display abnormal $\mathrm{Na}+$ channel activities. Muscle Nerve 31: 506-509.

36. Shaw DJ, Chaudhary S, Rundle SA, Crow S, Brook JD, et al. (1993) A study of DNA methylation in myotonic dystrophy. J Med Genet 30: 189-192.

37. Thyagarajan D, Byrne E, Noer S, Lertrit P, Utthanophol P, et al. (1991) Mitochondrial DNA sequence analysis in congenital myotonic dystrophy. Ann Neurol 30: 724-727.

38. Timchenko NA, Patel R, lakova P, Cai ZJ, Quan L, et al. (2004) Overexpression of CUG triplet repeat-binding protein, CUGBP1, in mice inhibits myogenesis. J Biol Chem 279: 13129-13139.

39. Floriach-Robert M, Cabello A, Simón De Las Heras R, Mateos Beato F (2001) [Neonatal hypotonia of muscular origin: analysis of 50 cases]. Neurologia 16 : 245-253.

40. Richer LP, Shevell MI, Miller SP (2001) Diagnostic profile of neonatal hypotonia: an 11-year study. Pediatr Neurol 25: 32-37.

41. Campbell C, Sherlock R, Jacob P, Blayney M (2004) Congenital myotonic dystrophy: assisted ventilation duration and outcome. Pediatrics 113: 811-816.

42. Tsilfidis C, MacKenzie AE, Mettler G, Barceló J, Korneluk RG (1992) Correlation between CTG trinucleotide repeat length and frequency of severe congenital myotonic dystrophy. Nat Genet 1: 192-195.

43. de Die-Smulders CE, Smeets HJ, Loots W, Anten HB, Mirandolle JF, et al.
(1997) Paternal transmission of congenital myotonic dystrophy. J Med Genet 34: 930-933.

44. Bergoffen J, Kant J, Sladky J, McDonald-McGinn D, Zackai EH, et al. (1994) Paternal transmission of congenital myotonic dystrophy. J Med Genet 31: 518520

45. Hunter A, Tsilfidis C, Mettler G, Jacob P, Mahadevan M, et al. (1992) The correlation of age of onset with CTG trinucleotide repeat amplification in myotonic dystrophy. J Med Genet 29: 774-779.

46. 46 Martorell L, Cobo A M, Parra J, Naudo M, Baiget M (2005) Prenatal diagnosis in Myotonic Dystrophy Type 1 (DM1): The Spanish experience. In 5th International Myotnonic Dystrophy Consortium Meeting (IDMC-5) Quebec City, Canada.

47. Cobo AM, Poza JJ, Martorell L, López de Munain A, Emparanza JI, et al. (1995) Contribution of molecular analyses to the estimation of the risk of congenita myotonic dystrophy. J Med Genet 32: 105-108.

48. Redman JB, Fenwick RG Jr, Fu YH, Pizzuti A, Caskey CT (1993) Relationship between parental trinucleotide GCT repeat length and severity of myotonic dystrophy in offspring. JAMA 269: 1960-1965.

49. Echenne B, Rideau A, Roubertie A, Sébire G, Rivier F, et al. (2008) Myotonic dystrophy type I in childhood Long-term evolution in patients surviving the neonatal period. Eur J Paediatr Neurol 12: 210-223.

50. Hecht BK, Donnelly A, Gedeon AK, Byard RW, Haan EA, et al. (1993) Direct molecular diagnosis of myotonic dystrophy. Clin Genet 43: 276-285.

51. Martorell L, Cobo AM, Baiget M, Naud $\tilde{A}^{3}$ M, Poza JJ, et al. (2007) Prenatal diagnosis in myotonic dystrophy type 1. Thirteen years of experience: implications for reproductive counselling in DM1 families. Prenat Diagn 27: 6872.

52. Faulkner CL, Kingston HM (1998) Knowledge, views, and experience of 25 women with myotonic dystrophy. J Med Genet 35: 1020-1025.

53. [No authors listed] (2000) New nomenclature and DNA testing guidelines for myotonic dystrophy type 1 (DM1). The International Myotonic Dystrophy Consortium (IDMC). Neurology 54: 1218-1221.

54. Harper PS (1975) Congenital myotonic dystrophy in Britain. I. Clinical aspects Arch Dis Child 50: 505-513.

55. Reardon W, Newcombe R, Fenton I, Sibert J, Harper PS (1993) The natura history of congenital myotonic dystrophy: mortality and long term clinical aspects. Arch Dis Child 68: 177-181.

56. Roig M, Balliu PR, Navarro C, Brugera R, Losada M (1994) Presentation, clinical course, and outcome of the congenital form of myotonic dystrophy. Pediatr Neurol 11: 208-213.

57. Hageman AT, Gabreëls FJ, Liem KD, Renkawek K, Boon JM (1993) Congenita myotonic dystrophy; a report on thirteen cases and a review of the literature. $J$ Neurol Sci 115: 95-9101.

58. Rudnik-Schöneborn S, Nicholson GA, Morgan G, Röhrig D, Zerres K (1998) Different patterns of obstetric complications in myotonic dystrophy in relation to the disease status of the fetus. Am J Med Genet 80: 314-321.

59. Rais-Bahrami K, MacDonald MG, Eng GD, Rosenbaum KN (1994) Persistent pulmonary hypertension in newborn infants with cogenital myotonic dystrophy J Pediatr 124: 634-635.

60. Rettwitz-Volk W, Wikstroem M, Flodmark O (2001) Occlusive hydrocephalus in congenital myotonic dystrophy. Brain Dev 23: 122-124.

61. Rutherford MA, Heckmatt JZ, Dubowitz V (1989) Congenital myotonic dystrophy: respiratory function at birth determines survival. Arch Dis Child 64 191-195.

62. Dodge PR, Gamstorp I, Byers RK, Russell P (1965) Myotonic dystrophy in infancy and childhood. Pediatrics 35: 3-19.

63. Bodensteiner JB, Grunow JE (1984) Gastroparesis in neonatal myotonic dystrophy. Muscle Nerve 7: 486-487.

64. Lee SY, Chan KY, Chow CB (1999) Survival of a 30-week baby with congenital myotonic dystrophy initially ventilated for 55 days. J Paediatr Child Health 35 313-314.

65. Keller C, Reynolds A, Lee B, Garcia-Prats J (1998) Congenital myotonic 
dystrophy requiring prolonged endotracheal and noninvasive assisted ventilation: not a uniformly fatal condition. Pediatrics 101: 704-706.

66. Wesström G, Bensch J, Schollin J (1986) Congenital myotonic dystrophy. Incidence, clinical aspects and early prognosis. Acta Paediatr Scand 75: 849854

67. Connolly MB, Roland EH, Hill A (1992) Clinical features for prediction of survival in neonatal muscle disease. Pediatr Neurol 8: 285-288.

68. Horan M, Stutchfield PR (2001) Severe congenital myotonic dystrophy and severe anaemia of prematurity in an infant of Jehovah's Witness parents. Dev Med Child Neurol 43: 346-349.

69. Campbell C, Magalhaes S, Lyttle B, Frewen T, Levin S (2005) Prolonged Ventilation in Congenital DM. In 5th International Myotonic Dystrophy Consortium Meeting, Quebec, Canada.

70. Wallgren-Pettersson C, Bushby K, Mellies U, Simonds A; ENMC (2004) 117th ENMC workshop: ventilatory support in congenital neuromuscular disorders -- congenital myopathies, congenital muscular dystrophies, congenital myotonic dystrophy and SMA (II) 4-6 April 2003, Naarden, The Netherlands Neuromuscul Disord 14: 56-69.

71. Johnson ER, Abresch RT, Carter GT, Kilmer DD, Fowler WM, et al. (1995) Profiles of Neuromuscular Diseases. Am J Phys Med Rehabil 74: S104-S116.

72. Kroksmark AK, Ekström AB, Björck E, Tulinius M (2005) Myotonic dystrophy: muscle involvement in relation to disease type and size of expanded CTGrepeat sequence. Dev Med Child Neurol 47: 478-485.

73. Sjögreen L, Engvall M, Ekström AB, Lohmander A, Kiliaridis S, et al. (2007) Orofacial dysfunction in children and adolescents with myotonic dystrophy. Dev Med Child Neurol 49: 18-22.

74. Nicholson A, Rivlin E, Sims DG, Chiswick ML, D'Souza SW (1990) Developmental delay in congenital myotonic dystrophy after neonatal intensive care. Early Hum Dev 22: 99-9103.

75. Martinello F, Piazza A, Pastorello E, Angelini C, Trevisan CP (1999) Clinical and neuroimaging study of central nervous system in congenital myotonic dystrophy. J Neurol 246: 186-192.

76. Steyaert J, Umans S, Willekens D, Legius E, Pijkels E, et al. (1997) A study of the cognitive and psychological profile in 16 children with congenital or juvenile myotonic dystrophy. Clin Genet 52: 135-141

77. Harley HG, Rundle SA, MacMillan JC, Myring J, Brook JD, et al. (1993) Size of the unstable CTG repeat sequence in relation to phenotype and parental transmission in myotonic dystrophy. Am J Hum Genet 52: 1164-1174.

78. Tanabe Y, lai M, Tamai K, Fujimoto N, Sugita K (1992) Neuroradiological findings in children with congenital myotonic dystrophy. Acta Paediatr 81: 613617.

79. Goossens E, Steyaert J, De Die-Smulders C, Willekens D, Fryns JP (2000) Emotional and behavioral profile and child psychiatric diagnosis in the childhood type of myotonic dystrophy. Genet Couns 11: 317-327.

80. Thompson A, Kaplan C, Gardner-Medwin D (1995) Congenital myotonic dystrophy. Pediatr Neurol 13: 85.

81. Regev R, de Vries LS, Heckmatt JZ, Dubowitz V (1987) Cerebral ventricular dilation in congenital myotonic dystrophy. J Pediatr 111: 372-376.

82. Garcia-Alix A, Cabañas F, Morales C, Pellicer A, Echevarria J, et al. (1991) Cerebral abnormalities in congenital myotonic dystrophy. Pediatr Neurol 7: 2832.

83. Wozniak JR, Mueller BA, Ward EE, Lim KO, Day JW (2011) White matter abnormalities and neurocognitive correlates in children and adolescents with myotonic dystrophy type 1: a diffusion tensor imaging study. Neuromuscul Disord 21: 89-96

84. Hashimoto T, Tayama M, Miyazaki M, Murakawa K, Kawai H, et al. (1995) Neuroimaging study of myotonic dystrophy. I. Magnetic resonance imaging of the brain. Brain Dev 17: 24-27.

85. Hashimoto T, Tayama M, Yoshimoto T, Miyazaki M, Harada M, et al. (1995)
Proton magnetic resonance spectroscopy of brain in congenital myotonic dystrophy. Pediatr Neurol 12: 335-340.

86. Haranaka M, Endo A, Kohira R, Fujita Y, Takada M, et al. (2000) [Brain lesion in congenital myotonic dystrophy]. No To Hattatsu 32: 268-273.

87. Canavese F, Sussman MD (2009) Orthopaedic manifestations of congenita myotonic dystrophy during childhood and adolescence. J Pediatr Orthop 29: 208-213.

88. Bassez G, Lazarus A, Desguerre I, Varin J, LaforÃat P, et al. (2004) Severe cardiac arrhythmias in young patients with myotonic dystrophy type 1 Neurology 63: 1939-1941.

89. Igarashi H, Momoi MY, Yamagata T, Shiraishi H, Eguchi I (1998) Hypertrophic cardiomyopathy in congenital myotonic dystrophy. Pediatr Neurol 18: 366-369.

90. Forsberg H, Olofsson BO, Eriksson A, Andersson S (1990) Cardiac involvement in congenital myotonic dystrophy. Br Heart J 63: 119-121.

91. Bu'Lock FA, Sood M, De Giovanni JV, Green SH (1999) Left ventricula diastolic function in congenital myotonic dystrophy. Arch Dis Child 80: 267-270.

92. Quera Salva MA, Blumen M, Jacquette A, Durand MC, Andre S, et al. (2006) Sleep disorders in childhood-onset myotonic dystrophy type 1. Neuromuscul Disord 16: 564-570.

93. Curry CJ, Chopra D, Finer NN (1988) Hydrops and pleural effusions in congenital myotonic dystrophy. J Pediatr 113: 555-557.

94. Stratton RF, Patterson RM (1993) DNA confirmation of congenital myotonic dystrophy in non-immune hydrops fetalis. Prenat Diagn 13: 1027-1030.

95. Cantagrel S, Chamboux C, Toutain A, Laugier J (1999) Congenital neonata myotonic dystrophy with persistent pulmonary hypertension and coma: a difficult diagnosis. J Perinat Med 27: 136-137.

96. Kimura S, Amemiya F, Fukazawa H (1987) Cystinuria with congenital myotonic dystrophy. Pediatr Neurol 3: 233-234.

97. Fujii T, Yorifuji T, Okuno T, Toyokuni S, Okada S, et al. (1991) Congenital myotonic dystrophy with progressive edema and hypoproteinemia. Brain Dev 13: $58-60$.

98. Blayney M, Clarke WN (1994) Persistent tunica vasculosa lentis as a sign of congenital myotonic dystrophy. J Pediatr Ophthalmol Strabismus 31: 384-386.

99. Sumi M, Kusumoto T, Tagawa M, Kondoh T, Ohno Y, et al. (2005) Two infantile cases of congenital myotonic dystrophy with cholelithiasis/cholestasis. Pediatr Int 47: 586-588.

100. Kasagi S, Shiota M, Ando M, Takeshita K (1989) [Hyperinsulinism in congenital myotonic dystrophy]. No To Hattatsu 21: 585-587.

101. Miyazaki M, Hashimoto T, Tayama M, Kuroda Y, Ueta T (1991) Congenital myotonic dystrophy associated with a chromosome pericentric inversion. Neuropediatrics 22: 181-183.

102. Teber S, Sezer T, Aypar E, Kendirli T, Atalay S, et al. (2010) Congenita myotonic dystrophy associated with Moebius syndrome and double-outlet right ventricle. Pediatr Int 52: 501-502. 